\title{
Beecbimtra iomopia
}

Володимир Перещ

ORCID iD 0000-0002-4962-4207

УДК 94(38)

DOI: $10.28925 / 2524-0757.2020 .2 .6$

\section{РОЛЬ БАСІЛЕВСІВ В ОРГАНІЗАЦІЇ РЕМІСНИЧОГО ВИРОБНИЦТВА ЗА ДАНИМИ ТАБЛИЧОК СЕРІї JN}

У статті на основі документів серії Jn досліджуються функції пілоських басілевсів. Застосовуючи комбінаторний метод, головнуувагу автор зосереджує на аналізі текстів табличок Jn 601 ma 431, у яких фіксується здійснення басілевсами функцій контролю за роботою ковалів. Аналізуючи ту роль, яку басілевси відіграють у табличках серії Jn загалом, і функції, які басілевс Аріqота виконує у тексті Jn 431 зокрема, автор показує, що басілевси не були скільки-небудь суттєво чи органічно пов'язані з ковалями, а функція контролю за їх роботою нав'язувалася басілевсам з боку палацу в окремих випадках і відігравала в їх діяльності другорядну роль.

Ключові слова: басілевс, qаsіrеи, серія Јn, лінійне письмо Б, мікенська цивілізація.

\section{Volodymyr Pereshch \\ THE PYLIAN BASILEIS ACCORDING TO THE TEXT OF THE JN SERIES}

The activities of the basileis, who appear in Homer's poems as tribal leaders, are associated with the organizing of handicraft production in the texts of linear B. Since the position of basileus, which appears before us for the first time in the Pylian and Knossos texts, continues to exist in the polis period, the study of the functions of the Achaean basileis will not only expand and deepen our knowledge of this position in the Mycenaean kingdoms of the second millennium, but will also allow us to reveal the transformational processes that this office underwent after the collapse of the palatial states of Greece and during the emergence of classical polis civilization. This article examines the Pylian texts of the Jn series, which record the basileis' fulfillment of the function of managing (overseeing) the work of the smiths. The work is based on the so-called combinatorial method, which provides in-depth study of the internal structure of texts as a fundamental stage of penetration into their content. Applying this method, the author recognizes four distinct sections in the document Jn 431: apekean smiths who have tarasija; apekean smiths, who do not have tarasija; apekean smiths of Potnia, who have tarasija; apekean smiths of Potnia, who do not have tarasija. This division allows us to conclude that the basileus Apiqota only supervises the work of the apekean smiths who have tarasija, and is not associated with the apekean smiths who do not have tarasija.

Analasing the role played by the basileis in the Jn series in general and the functions that the basileus Apiqota performs in the text of Jn 431 in particular, and also based on the fact that the basis of basileis' activity was concentrated in the qasirewija headed by them, the author concludes that the basileis were not in any way substantially or organically connected with the smiths, and the function of controlling their work was imposed on the basileis by the palace in certain individual cases (Jn 431, 691, 845) and played a secondary role in their activities.

Key words: basileus, qasireu, Jn series, linear B, Mycenaean civilization.

( Київський університет імені Бориса Грінченка, 2020

(c) Перещ В., 2020 
письма Б пов'язуе іяльність басілевсів, котрі в поемах Гомера фігурують як племінні вожді, у текстах лінійного го виробництва. Оскільки посада басілевса, що з'являється вперше у пілоських та кносських текстах, продовжує існувати і в полісну добу, дослідження функцій ахейських басілевсів не лише розширить і поглибить наші знання про цю посаду в мікенських царствах II тис. до н.е., а й дозволить розкрити ті трансформаційні процеси, які були нею пройдені після колапсу палацових держав Греції, у період зародження класичної полісної цивілізації.

Дослідження текстів лінійного письма Б загалом і табличок серії Jn зокрема було започатковано М. Вентрісом і Дж. Чадвіком - британськими дослідниками, котрі дешифрували ці тексти на сторінках фундаментальної роботи "Documents in Mycenaean Greek" (Ventris M., Chadwick J., 1973. Р. 352-356). Питань, пов’язаних з басілевсами, під час вивчення текстів 3 палацових архівів торкалися такі дослідники, як М. Лежен, Л. Палмер, М. Ленг, Г.Ф. Полякова, Дж. Сміт, П. Карльє, Дж. Кілен, М. Нош, С. Ніколудіс, Б. Монтекі, Д. Накассіс та інші (Lejeune M., 1961. P. 409-434; Palmer L., 1963. Р.279-289; Lang M., 1966. Р. 397-412; Полякова Г.Ф., 1978. C. 224-237; Smith J.S., 1992-1993. P. 167-259; Carlier P., 1995. P. 355-364; Killen J.T., 2001. P. 161180; Nosch M.-L., 2006. P. 161-182; Nikoloudis S., 2006. P. 165-169; Montecchi B., 2012. P. 185-194; Nakassis D., 2013. Р. 74-80). Особливо слід відмітити грунтовну роботу П. Карльє, присвячену суто басілевсам лінійного письма Б, посилання на яку серед спеціалістів стало обов'язковим.

Однак деякі важливі моменти, зокрема у дослідженні ролі басілевса Apiqota 3 тексту Jn 431, залишилися поза увагою вчених. Враховуючи все це, ми визначили як мету статті аналіз ролі басілевсів, котрі фігурують у текстах серії Jn, в організації ремісничого виробництва.

Три басілевси згадуються у пілоських табличках cepiï Jn (Olivier J.-P., Del Freo M., 2020. P. 159-172): qasireu Apiqota (Jn 431), qasireu Paqosijo (Jn 601) та Erikowo qasireu (Jn 845). Проаналізуємо один $з$ цих текстів:

Jn 601

1 po-wi-te-ja, ka-ke-we, ta-ra-si-ja, e-ko-te

2 wo-di-jo, AES M 6 to-ro-wi AES M 8 e-u-po-ro-wo AES M 8

3 o-qa AES M 4 te-u-to AES M $5 \mathrm{pu}_{2}$-ti-ja AES M 6

M 8

4 po-to-re-ma-ta AES M 8 wa-pa-no AES

5 po-so-ro AES M 8 mo-da AES M 8 pe-po-ro AES M 4

6 o-na-se-u AES M 12 vest.[ ]AES M 7[ ] vac.
7 ko-to-wa-p̣e[ ]AES M 8 țọ[-so-]de, e-p̣ida-to AES M $\dot{7}$

8 qa-si-re-u, pa-qo-si[-jo ]1 [

9 to-so-pa, ka-ko [ ] AES L 3 M $1\llcorner$ 4[

10 vac. [ ] vac. [ ] vac. [ ] vac.

11 to-so-de , a[-ta-ra-]si-jo[ ka-ke-we po-] ti-na-jo 1

12 po-so-ri-jo[ 1 ] vest. [ ]ne-wo 1

i-pe-ra-ta 1

13 sa-nu-[ ] 1 [ ] vac. [ ]! vac.

На початку цього документа, у першому рядку, вказується регіон Пілоської держави powiteja, - якого стосується зміст таблички, і фігурує формула "kakewe tarasija ekote" (ковалі, що мають tarasija). У мікенології термін “tarasija” пов'язується 3 виробництвом, що організовується безпосередньо палацовою адміністрацією, і передбачає постачання ковалям або ткачам певної кількості зваженої сировини (вовна і бронза) для переробки іiі у готову продукцію, яка потім повернеться до палацу (Lejeune M., 1961. P. 419; Ventris M., Chadwick J., 1973. P. 252, 583; Killen J.T., 2001. P. 161-180; Nosch M.-L., 2006. P. 161-182; Montecchi B., 2012. Р. 185). У радянській традиції такий термін перекладається як «завдання» (Полякова Г.Ф., 1978. С. 232). Тобто, конструкція «kakewe tarasija ekote» може бути перекладеною як «ковалі, що мають завдання».

Далі перераховуються власні імена ковалів із зазначенням кількості бронзи, яку вони отримують, вказується титул і ім'я басілевса - qasireu Paqosijo - та загальна кількість бронзи. Потім, після пустого рядка, з'являється конструкція "tosode atarasijo kakewe" («стільки ковалів не мають завдання») і перераховуються імена цих ковалів.

Таким чином, ми бачимо, що у цьому тексті йдеться про видачу бронзи ковалям. Як можна зрозуміти, усі ковалі, перераховані у документі, належать до регіону Powiteja. Одні з них (kakewe tarasija ekote) отримали завдання та їхні повинності на користь палацу зараховуватимуться за результатами їх роботи. Інших же ковалів, котрі не отримали завдання (aratasijo kakewe), палац реєструє, очевидно, 3 тією метою, щоб стягнути з них ці повинності пізніше (про ковалів табличок серії Jn див. особливо: Ventris M., Chadwick J., 1973. P. 351-356, 508-511; Lejeune M., 1961. P. 401-434; Montecchi B., 2012. P. 185-194; Nakassis D., 2013. P. 74-80.)

Що ж стосується басілевса Paqosijo, то тут необхідно зазначити, що таблички Jn 431 i 845, де згадуються інші два басілевси - Apiqota i Erikowo, - мають майже таку саму структуру, що й Jn 601. Тож, усі три басілевси фігурують практично в ідентичних позиціях. Вони не належать ані до категорії ковалів, що отримали завдання (kakewe tarasija ekote), ані до категоріiі, що його не отримали (atarasijo kakewe); 
фігурують одразу після списку ковалів із завданням (kakewe tarasija ekote), проте самі вони, на відміну від ковалів, не отримують жодного завдання (tarasija). Натомість у рядку одразу після басілевсів вказується загальна кількість металу, виданого ковалям, котрі мають завдання. Усе це дозволяє стверджувати, що басілевси здійснюють тут функції певного контролю за роботою ковалів і несуть відповідальність перед палацом за процес і результат їхної роботи (Carlier P., 1995. Р. 356.) або ж, хоча 6, контролюють доставку бронзи цим ковалям (Smith J.S., P. 190-191; Montecchi B., 2012. P. 188).

Інші таблички серії Jn (всього дана серія нараховує 27 текстів) побудовані за тими ж принципами, що i Jn 601, 431, 845, але 3 тією відмінністю, що в них відсутні згадки про басілевсів. Наприклад:

Jn 389

1 ạ-ka-si-jo-ne, ka-ke-we, ta-ra-si-ja, e-ko-te

2 pi-ra-me-no AES M 3 ma-u-ti-jo AES

M 3 e-do-mo-ne-u AES M 3

3 ka-ra-wi-ko AES M 1 N 2 pi-we-ri-ja-ta AES $\quad M \quad 1 \quad N \quad 2$

4 sa-mu-ta-jo AES M 1 N 2 wa-u-do-no

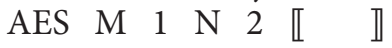

5 ka-ra-pa-so AES M 1 N 2 pi-ta-ke-u AES $\quad M \quad 1 \quad N \quad 2$

$$
6 \text { mo-re-u AES M } 1 \text { N } 2 \text { ti-ta-[•-]wo }
$$

AES M 3

7 to-so-de, e-pi-da-to, ka-ko, pa-șị AES M 6

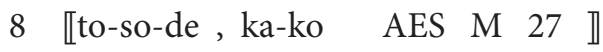

9 to-so-de ka-ko AES M 27

10 vac.

11 to-so-de, a-ta-ra-si-jo , ka-ke-we ,

12 te-te-re-u 1 pa-pa-jo 1 pi-ro-we-ko 1

$\mathrm{a}_{2}$-nu-me-no 1

13 ko-so-u-to 1

Як бачимо, на початку цього документа, як і в проаналізованому нами вище тексті Jn 601, фігурує назва області та конструкція "kakewe tarasija ekote”. Далі перераховуються імена ковалів і вказується кількість бронзи, яку кожен 3 них отримує, фіксується загальна кількість металу та реєструються імена atarasijo kakewe. Однак про басілевсів жодної згадки при цьому немає.

Було багато спроб пояснити наявність басілевсів в одних і відсутність їх в інших текстах cepiï Jn (Lang M., 1966. P. 401; Ventris M., Chadwick J., 1973. P. 352-356; Palmer L., 1963. P. 279-289; Lejeune M., 1961. P. 409-431). Зокрема цікавим $є$ припущення Г.Ф. Полякової, котра намагалась довести, що функції басілевсів виконували, власне, самі ковалі (Полякова Г.Ф., 1978. С. 233-234). Однак, на нашу думку, наведені авторкою на користь цієї гіпотези аргументи здаються непереконливими, про що ми говоримо детально в іншій роботі (Перещ В.М. Пілоські ковалі і басілевси; у друку). Правий же, либонь, був П. Карльє, говорячи, що більш-менш нечаста поява басілевсів у серії Jn засвідчує, що їх зв’ язок 3 ковалями був випадковим (Carlier P., 1995. P. 356; також: Nikoloudis S., 2006. P. 168).

До цього необхідно додати, що басілевси, власне, у самих списках ковалів серії Jn з'являються у якості загалом не властивих для цієї серії, можна сказати, «додаткових» фігур. Особливо це відчувається у тексті Jn 431, де фігурує басілевс Apiqota: Jn 431

1 a-pe-ke-i-jo, ka-ke-we, ta-ra-si[-ja, e-ko-te

2 wi-ja-ni-jo AES M 5 ka-ra-*82 [] AES M 5 [] ko-tu-ro ${ }_{2}$ AES M 5

3 ma-na-si-we-ko AES $M$ da-ma-so AES M 5 qe-ta-ko AES M 4
4 a-ko-to-wo
AES M 7 u[ ]i-jo

AES

M 6 [[ ] ]

5 ma-wa-si-jo AES M 5 qe-to-ro-no AES M 7

6 qa-si-re-u, a-pi-qo-ta 1 [ ] i- ${ }^{\star} 65$-qe 1

7 to-so-de, ka-ko, AES [L 1] M 24

8 vacat [ ] vacat

9 to-so-de, a-ta-ra-si-jo, ka-ke[-we ] vacat 10 a-ta-tu-ro 1 i-ta-ra-jo 1 sa [ 1] vacat 11 wi-ja-te-wo 1 no-e-u 1 nu-ri-ja-jo 1 qe-ta-ko-jo, do-e-ro 1

12 a-ka-ma-wo 1 epe-ke-u $1{ }^{*} 82$-de 1 pu-te-u 1

13 ko-ne-wa-ta 1 qe-to-ro-no 1 mo-re-u 1 a-eri-qo 1

$14 \quad$ vacat

16 a-pe-ke-e, ka-ke-we, po-ti-ni-ja-we-jo , ta-ra-si-ja, e-ko-te

17 ko-za-ro AES M 6 a-ke-wa-ta AES M 3 sa-ke-re-u AES M 6

18 we-we-si-jo AES M 3 ko-ta-wo AES M 3 da-u-ta-ro AES M 6

$\begin{array}{lll}19 & \text { vacat } & \\ 20 & \text { to-so-de }, & \text { ka-ko } \\ 21 & \text { vacat } & \text { AES M } 27\end{array}$

22 to[-so-de] , a[-ta-]ra-si-jo , ka-ke-we , ka-ri-se-u 1 du-ko-so [1

$23 \mathrm{ko}[\quad] 1 \quad$ e-u-wa-ko-ro 1 ke-we-no 1 a-ta-o 1 [

24 ]wa-ti-ro 1 me-ri-wa-[.] 1

25 ]i-je-re[ ]VIR 10 to-sa-no-jo VIR 5

26 VIR] 1 a-mu-ta-wo-no VIR 31

Як бачимо, крім звичних для нас kakewe tarasija ekote та atarasijo kakewe, у другій половині тексту з'являються ще й ковалі Потнії (kakewe potinijawejo). Загалом можемо визначити, що у цьому документі ковалі поселення Апекея поділяються писцем на: apekee kakewe potinijawejo (апекейські ковалі Потніï) i, власне, apekeijo kakewe (апекейські ковалі); як ті, так і інші розділені, у свою чергу, на kakewe tarasijo ekote (ті, що мають завдання) i atarasijo kakewe (ті, що не мають завдання). Таким чином, текст, по суті, містить чотири секції: 1) апекейські ковалі, котрі 
мають завдання (рядки 1-8); 2) апекейські ковалі, які не мають завдання (рядки 10-13); 3) апекейські ковалі Потнії, котрі мають завдання (рядки 16-20); 4) апекейські ковалі Потнії, які не мають завдання (рядки 22-26).

У документі немає протиставлення ковалів басілевса ковалям Потнії; тут апекейські ковалі Потніï (apekee kakewe potinijawejo) протиставляються апекейським ковалям, не пов'язаним 3 Потніює (apekeijo kakewe). Також, вписуючи басілевса у першу секцію ковалів, писець одночасно відокремлює його незаповненим рядком від ковалів, котрі не мають завдання. Усе це дозволяє нам зробити висновок, що басілевс Apiqota здійснює контроль лише за роботою апекейських ковалів, що отримали tarasija (ковалі першої секціiі), і не дотичний до апекейських ковалів, що не отримали tarasija (ковалі другої секціï).

Виокремлення писцем 3 усього загалу апекейських ковалів тих, котрі характеризуються як apekee kakewe potinijawejo (апекейські ковалі Потніі), можна сприймати як вказівку й на те, що апекейський храм Потнії, поряд з постатями 3 палацу, котрі видавали бронзу і приймали готові вироби з неї, виконував певні організаторські та контролюючі функції у роботі ковалів. Причому організаторська діяльність храмової адміністрації не обмежувалася лише контролем за ковалями, що отримали завдання (kakewe tarasija ekote), але поширювалася й на ковалів, що його не отримали (atarasijo kakewe). Такого висновку ми доходимо на основі того, що храмова адміністрація, яка у тексті приховується за терміном potinijawejo, фігурує не наприкінці однієї з двох секцій, як це ми бачимо у випадку з басілевсом, а на початку третьої секції, формулюючи при цьому загальний заголовок як для третьої секції, так і для четвертої.

На фоні цього басілевс Apikota, контролюючи лише ковалів, котрі отримали завдання, і не маючи стосунку до ковалів, які його не отримали, виглядає не як місцевий лідер, глава общини, що піклується про найважливіші справи свого поселення, а як палацовий функціонер, до компетенції якого входить виконання чітко окресленого державою завдання - контролю за роботою тих ковалів, що отримали tarasija. У свою чергу, апекейські ковалі виступають тут не як общинники, підпорядковані главі общини, а як особи, тимчасово підконтрольні призначеному палацом чиновнику.

Така роль басілевсів у пов'язаних 3 ремісничим виробництвом текстах серії Jn виразно контрастує 3 тією позицією, яку вони посідають у так званих басілейях (qasirewija), про які йдеться у табличках KN As 1516, К 875; PY Fn 50 (Chadwick J., Killen J.T., Olivier J.P., 2012; Перещ B.M. Rawakeja i qasirewija за даними текстів лінійного письма Б; у друку). Тут басілевси фігурують як безпосередні лідери та організатори цих колективів, а самі вказівки на басілевсів як на таких лідерів, на відміну від згадок про них у серії Jn, є центральними, структуроутворюючими записами цих документів. Враховуючи це, можемо сказати, що басілевси не були скількинебудь суттєво чи органічно пов'язані з ковалями, але функція контролю за роботою їх нав'язувалася басілевсам з боку палацу лише у певних окремих випадках (Jn 431, 691, 845) і була в їхній діяльності другорядною.

Таким чином, у текстах серії Jn фіксується здійснення басілевсами функцій контролю за роботою ковалів. Документ Jn 431 містить чотири секції: апекейські ковалі, котрі мають tarasija; апекейські ковалі, які не мають tarasija; апекейські ковалі Потнії, котрі мають tarasija; апекейські ковалі Потнії, які не мають tarasija. Басілевс Apiqota здійснює контроль лише за роботою апекейських ковалів, котрі отримали tarasija (ковалі першої секціï) і не дотичний до апекейських ковалів, які не отримали tarasija (ковалі другої секції). 3 іншого боку, порівнюючи у тексті позиції басілевса й храмової адміністрації (виражена терміном potinijawejo у третій секціï), ми можемо стверджувати, що, на відміну від басілевса, ця адміністрація не обмежувалася контролем лише за роботою ковалів, що отримали tarasija (третя секція), але поширювала його й на ковалів, що не отримали tarasija (четверта секція).

Враховуючи ту роль, що їі басілевси відіграють у серії Jn загалом, і ті функції, які басілевс Apiqota виконує у тексті Jn 431 зокрема, а також виходячи 3 того, що основа діяльності басілевсів зосереджувалася в очолюваних ними басілейях (qasirewija), маємо підстави ствреджувати, що басілевси не були хоч якось суттєво чи органічно пов'язані з ковалями, а функція контролю за роботою ї нав'язувалася басілевсам з боку палацу лише у певних випадках (Jn 431, 691, 845) і була для них другорядною. У контексті цієї функції басілевс Apiqota фігурує не як місцевий лідер, глава общини, котрий несе відповідальність принаймні за ковалів, непідпорядкованих храмовій адміністрації поселення, а як палацовий функціонер, до компетенції якого входить виконання чітко окресленого державою завдання.

Зроблені висновки змушують поставити питання: якщо басілевс був палацовим функціонером, то чи була його діяльність пов'язана виключно з поселенням, у якому він був місцевим лідером, чи ж використовувалася палацом i у загальнодержавних масштабах? Відповідь на це питання потребує окремого комплексного дослідження, де мають бути проаналізовані не лише всі документи, в яких згадуються басілевси, але й тексти, де фігурують усі інші палацові функціонери ахейських царств. 


\section{ДЖЕРЕЛА}

1. Полякова Г.Ф. Социально-политическая структура пилосского общества (по данным линейного письма В). Москва: Наука, 1978. 272 с.

2. Carlier P. Qa-si-re-u et qa-si-re-wi-ja. In Politeia: Society and State in the Aegean Bronze Age (Aegaeum 12) / ed. R. Laffineur and W.-D. Niemeier. Liège; Austin, 1995. P. 355-364.

3. Chadwick J., Killen J.T., Olivier J.P. The Knossos Tablets. Cambridge: Cambridge University Press, 2012. $488 \mathrm{p}$.

4. Killen J.T. Some Thoughts on ta-ra-si-ja. Economy and Politics in the Mycenaean Palace States. Proceedings of a Conference held on 1-3 July 1999 in the Faculty of Classics. Cambridge, 2001. P. 161-180.

5. Lang M. Jn Formulas and Groups. Hesperia. 1966. № 35. P. 397-412.

6. Lejeune M. Les forgerons de Pylos. Historia.1961. Bd. 10. H. 4. P. 409-434.

7. Montecchi B. Wool-Spinning, Bronze-Working and the Peculiarities of Mycenaean ta-ra-si-ja. In Pasiphae. Rivista di filologia e antichita Agee / ed. F. Serra. Pisa; Roma, 2012. P. 185-194.

8. Nakassis D. Individuals and Society in Mycenaean Pylos. Leiden and Boston: BRILL, 2013. 448 p.

9. Nikoloudis S. The rawaketa, Ministerial Authority and Mycenaean Cultural Identity. PhD Dissertation. University of Texas at Austin. Austin, 2006. 280 p.

10. Nosch M.-L. More Thoughts on the Mycenaean ta-ra-si-ja System. In Fiscality in Mycenaean and Near Eastern Archives. Proceedings of the Conference held at Soprintendenza Archivistica per la Campania, Naples 21-23 October 2004 / ed. M. Perna. Napoli, 2006. P. 161-182.

11. Olivier J.-P., Del Freo M. The Pylos Tablets Transcribed: deuxième édition. Padova: Libreriauniversitaria.it edizioni Webster srl, 2020. 408 p.

12. Palmer L. The Interpretation of Mycenaean Greek Texts. Oxford: Clarendon Press; Toronto: Oxford University Press, 1963. XVI, 488 p.

13. Smith J.S. The Pylos Jn series. Minos. 1992-1993. № 27-28. P. 167-259.

14. Ventris M., Chadwick J. Documents in Mycenaean Greek, 2nd ed. Cambridge: Cambridge University Press, $1973.622 \mathrm{p}$.

\section{REFERENCES}

1. Carlier, P. (1995). Qa-si-re-u et qa-si-re-wi-ja [Qa-si-re-u and qa-si-re-wi-ja] (R. Laffineur, W.-D. Niemeier / Ed.). Politeia [in French].

2. Chadwick J., Killen J. T., Olivier J. P. (2012). The Knossos Tablets. Cambridge: Cambridge University Press [in English].

3. Killen, J. T. (2001). Some Thoughts on ta-ra-si-ja. Economy and Politics in the Mycenaean Palace States. Proceedings of a Conference held on 1-3 July 1999 in the Faculty of Classics, pp. 161-180, Cambridge [in English].

4. Lang, M. (1966). Jn Formulas and Groups. Hesperia, 35, 397-412 [in English].

5. Lejeune, M. (1961). Les forgerons de Pylos. Historia, 10.4, 409-434 [in French].

6. Montecchi, B. (2012). Wool-Spinning, Bronze-Working and the peculiarities of Mycenaean ta-ra-si-ja. (F. Serra / Ed.). Pasiphae, Rivista di filologia e antichita Agee [in English].

7. Nakassis, D. (2013). Individuals and Society in Mycenaean Pylos. Leiden and Boston: BRILL [in English].

8. Nikoloudis, S. (2006). The rawaketa, Ministerial Authority and Mycenaean Cultural Identity [The rawaketa, Ministerial Authority and Mycenaean Cultural Identity]. PhD Dissertation, Austin [in English].

9. Nosch, M.-L. (2006). More Thoughts on the Mycenaean ta-ra-si-ja System. (M. Perna / Ed.), Fiscality in Mycenaean and Near Eastern Archives [in English].

10. Olivier, J.-P. (2020). Del Freo M. The Pylos Tablets Transcribed: deuxième édition. Padova: Libreriauniversitaria.it edizioni Webster srl. [in French].

11. Palmer, L. (1963). The Interpretation of Mycenaean Greek Texts. Oxford: Clarendon Press; Toronto: Oxford University Press. [in English].

12. Polyakova, G. F. (1978). Socialno-politicheskaia struktura pilosskoho obshchestva (po dannym lineinoho pisma B). Moskva: Nauka [in Russian].

13. Smith, J. S. (1992-1993). The Pylos Jn series. Minos, 27-28, 167-259 [in English].

14. Ventris, M., Chadwick J. (1973). Documents in Mycenaean Greek, 2nd ed. Cambridge: Cambridge University Press [in English].

Дата надходження статті до редакції: 15.08.2020. 